\title{
Incidence and predictors of tuberculosis among HIV patients after initiation of antiretroviral treatment in Ethiopia: a systematic review and meta-analysis
}

Melkalem Mamuye Azanaw', Nebiyu Mekonnen Derseh², Gebeyehu Shumuye Yetemegn ${ }^{2}$ and Dessie Abebaw Angaw ${ }^{3^{*}}$ (D)

\begin{abstract}
Background: Tuberculosis is the oldest infectious disease and it is still the leading cause of morbidity and mortality worldwide. Even though several primary studies have been conducted on the incidence of tuberculosis among HIV-infected individuals in Ethiopia, national-level tuberculosis incidence is unknown. Therefore, this study is aimed to assess the TB incidence rate and its predictors among HIV-infected individuals after the initiation of ART in Ethiopia.

Methods: We conducted an extensive search of literature as indicated in the guideline of reporting systematic review and meta-analysis (PRISMA). The databases used were PubMed, Google Scholar, and HINARI literature. We used the Joanna Briggs Institute (JBI) Meta-Analysis of Statistics Assessment and Review Instrument for critical appraisal of studies. The meta-analysis and Meta regressions were conducted using STATA 14 software. Met-analysis and meta-regression were computed to present the pooled incidence rate and predictors of tuberculosis among HIV-infected patients after initiation of ART with a 95\% confidence interval.

Results: Among a total of 189 studies, 11 studies were included in this analysis. The estimated pooled incidence rate of TB per 100-person year observation (PYO) among HIV-infected patients after initiation of ART therapy was 4.8(95\% Cl 3.69-5.83). In subgroup analysis, the estimated pooled incidence of tuberculosis showed a slight difference between adults and children after initiation of ART treatment, which was $4.3(95 \% \mathrm{Cl} 2.96,5.71)$ and 5.0 ( $95 \% \mathrm{Cl} 3.51,6.50)$, respectively. Significantly pooled estimates of predictors of TB incidence by a meta-analysis were being anemic $(2.30,95 \% \mathrm{Cl} 1.75,3.02)$; on clinical stages III and IV $(2.26,95 \% \mathrm{Cl} 1.70,3.02)$; and not on cotrimoxazole preventive therapy (CPT) $(2.16,95 \% \mathrm{Cl} 1.23,3.72)$. Besides, a meta-regression revealed that CD4 $<200 \mathrm{cells} / \mathrm{mm}^{3}$ $(2.12,95 \% \mathrm{Cl} 1.17,3.86)$ was a positive significant predictor of TB among HIV patients after the initiation of ART.

(Continued on next page)
\end{abstract}

\footnotetext{
* Correspondence: dessieabebaw96@gmail.com

${ }^{3}$ Department of Epidemiology and Biostatistics, Institute of Public Health, College of Medicine and Health Science, University of Gondar, Gondar,

Ethiopia

Full list of author information is available at the end of the article
}

(c) The Author(s). 2021 Open Access This article is licensed under a Creative Commons Attribution 4.0 International License, which permits use, sharing, adaptation, distribution and reproduction in any medium or format, as long as you give appropriate credit to the original author(s) and the source, provide a link to the Creative Commons licence, and indicate if changes were made. The images or other third party material in this article are included in the article's Creative Commons licence, unless indicated otherwise in a credit line to the material. If material is not included in the article's Creative Commons licence and your intended use is not permitted by statutory regulation or exceeds the permitted use, you will need to obtain permission directly from the copyright holder. To view a copy of this licence, visit http://creativecommons.org/licenses/by/4.0/. 
(Continued from previous page)

Conclusions: The current study showed that the pooled incidence of TB among HIV patients was found to be lower than the WHO 2018 national estimate. Being anemic, WHO stages III and IV, not on CPT, CD4<200cells/ $\mu$ l, and being male were significant predictors of tuberculosis. Therefore, the existing strategies to decrease TB should be strengthening.

Study protocol registration: CRD42020155573.

Keywords: Incidence, TB, HIV, After ART initiation and Ethiopia

\section{Background}

Tuberculosis (TB) is the oldest infectious disease and it is still the leading cause of morbidity and mortality worldwide [1]. Human immunodeficiency virus-infected people are at the highest risk for developing TB of which 22 times more likely to be ill with TB than those without HIV. Human immunodeficiency virus infection is the main risk factor for active tuberculosis disease [2] and 10\% higher rates of progression from latent to active $\mathrm{TB}$ that leads to more severe disseminated disease presentation and increased mortality. An estimated 862, 000 people with HIV fell ill TB in 2018 and 251,000 deaths [3].

Despite the widespread use of ART with isoniazid preventive therapy (IPT), intensified case finding, and infection control as a whole the three WHOI's strategy in Ethiopia, tuberculosis is the common cause of morbidity and mortality among HIV patients. According to the WHO global TB report, 2018, Ethiopia had an estimated 12000 incident TB per 100,000 population among HIV infected individuals [1].

Although HIV itself is the main risk factor for active TB disease, there are possible additional aggravating factors. Based on previous studies, low CD4 count, advanced WHO clinical stage, ambulatory or bedridden functional status, being anemic, undernutrition, OIs, DM, high viral load, and increased family size in adults were positive predictors of TB incidence, and the above plus delayed motor development and inappropriate vaccination for BCG were the predictors of incident TB cases among individuals on ART [4-9], while both cotrimoxazole preventive therapy (CPT) and IPT reduced TB incidence [7, 10-15].

Different efforts have been implemented to integrate TB diagnosis and treatment with HIV care to manage TB among HIV-infected individuals, though TB still occur in HIV patients who are on antiretroviral treatment. Although several primary studies have been conducted on the incidence of TB among HIV-infected individuals in Ethiopia, there are no aggregated nationallevel studies after ART initiation. Therefore, this systematic review and meta-analysis aimed to estimate the pooled incidence and predictors of tuberculosis among HIV-infected individuals after ART initiation in Ethiopia so as important to design interventions and prevention mechanisms for further improvement of quality of life among people living human immunodeficiency virus (PLHIV). Furthermore, this study will inform health workers and other stakeholders to make early screening and detection of TB in PLHIV as TB can occur in any course of HIV treatment.

\section{Methods}

\section{Reporting and protocol registration}

This systematic review and meta-analysis was reported as indicated in the guideline of reporting systematic review and meta-analysis (PRISMA) [16]. The protocol used in this study was registered with the International Prospective Register of Systematic Reviews (PROSPERO) and can be accessed with the registration number CRD42020155573.

\section{Searching strategy}

We used search engines PubMed, HINARI, Google scholar, and free Google databases in parallel using search strings adapted to the requirements of each database. We conducted search for PubMed/Medline search engine by using the entry term as: $(((($ "knowledge"[MeSH Terms] OR "knowledge"[All Fields]) AND ("attitude"[MeSH Terms] OR :attitude"[All Fields])) AND ("perception"[MeSH Terms] OR "perception"[All Fields])) AND "practice"[All Fields]) AND ("severe acute respiratory syndrome coronavirus 2"[Supplementary Concept] OR "severe acute respiratory syndrome coronavirus 2"[All Fields] OR "ncov"[All Fields] OR "2019-nCoV"[All Fields] OR “COVID19"[All Fields] OR "SARS-CoV-2"[All Fields] OR ((coronavirus[All Fields] OR “cov"[All Fields]) AND 2019/ 11[PubDate] AND ("students"[MeSH Terms] OR "students"[All Fields]). We used specific-subject headings for the other databases (HINARI and Google Scholar). Besides, to identify other relevant articles, we manually searched the reference lists of eligible articles.

\section{Eligibility criteria}

Three independent reviewers (MM, NM, and GS) screened all titles and abstracts of the articles before the full-text review. Full texts were then screened by the same reviewers according to the pre-specified inclusion and exclusion criteria. The majority (two thirds) of the 
reviewers' agreement has been taken for screened paper and eligibility for systematic review and meta-analysis.

\section{Inclusion criteria}

We included only people who took ART as study population, reporting as TB incidence rate and predictors among HIV patients, articles published in English language, studies done in Ethiopia, and articles published between 1st January 2010 and 31st October 2019.

\section{Exclusion criteria}

We excluded reviewed papers for the same objectives, those papers exclusively reporting multi-drug or extensively drug-resistant (MDR/XDR), TB as outcomes, and studies other than in humans.

\section{Extraction of data from eligible papers}

Data were extracted for each included study as the name of the first author, date of publication, study setting, target population, study region, study area, study design, sample size, diseased (new TB case), person-year observation, incidence rate per 100-person-year observation, and predictors (risk estimate (HR) and their 95\% confidence interval) by using standardized data extraction form (Table 1). Data extraction from selected articles was done independently by three reviews. Disagreements were resolved by $2 / 3$ of the reviewers' consensus.

\section{Quality assessment for studies}

Study quality was assessed using a standardized tool adapted from the JBI tool for cohort studies. The tool was considering the following study characteristics: sampling representative and size, exclusion of TB at cohort entry, outcomes ascertainment during follow-up, and duration of follow-up. Studies fulfilling the required criteria as score 1 and studies with scores 0 were considered to be of poor quality for specified criteria. No studies were excluded from the reviews based on their quality scores [23].

\section{Data management and processing}

The outputs from the searching engines were imported into Endnote Version 7.1 software and duplicates were removed. Data were recorded on the abstraction forms and entered into an Excel 2013 sheet (Microsoft Corporation, WA, USA) and then exported to Stata version 14 for analysis.

\section{Data synthesis and analysis}

Both systematic review and meta-analysis were done by using STATA 14 software. In the qualitative part of the review, all eligible articles reporting as TB incidence rate among HIV-positive individuals were summarized according to the target age group, study regions, and study setting. We computed the incidence rates, and confidence intervals for studies that only reported the number of TB cases and person-years of follow-up for the different strata in the cohort, using Stata version 14 software.

Meta-analyses (quantitative reviews) were conducted to determine the overall pooled incidence rate of $\mathrm{TB}$ among HIV infected individuals across different categories or strata. Heterogeneity was evaluated using the Cochran statistic and the $I^{2}$ statistics [24]. The magnitude of statistical heterogeneity between studies was assessed using $I^{2}$ statistics and values of 25, 50, and 75\% were considered to represent low, medium, and high, respectively. The random-effects model was used for the data identified as heterogeneous during analysis. Metaanalyses and meta-regression were performed using Stata software version 14.1. For the incidence of

Table 1 Characteristics of included studies with the outcome of the studies $(n=11)$

\begin{tabular}{|c|c|c|c|c|c|c|c|c|c|}
\hline $\begin{array}{l}\text { The author with a } \\
\text { publication year }\end{array}$ & $\begin{array}{l}\text { Study } \\
\text { region }\end{array}$ & $\begin{array}{l}\text { Study } \\
\text { design }\end{array}$ & $\begin{array}{l}\text { Study } \\
\text { population }\end{array}$ & $\begin{array}{l}\text { Follow-up time } \\
\text { (months) }\end{array}$ & $\begin{array}{l}\text { Sample } \\
\text { size }\end{array}$ & $\begin{array}{l}\text { TB } \\
\text { case }\end{array}$ & $\begin{array}{l}\text { Total } \\
\text { PYO }\end{array}$ & $\begin{array}{l}\text { IR per } 100 \\
\text { PYO }\end{array}$ & $\begin{array}{l}\text { Study } \\
\text { quality }\end{array}$ \\
\hline Ayalaw et al., 2015 [13] & Amhara & RFS & Children & 72 & 271 & 52 & 1100.5 & 4.73 & Good \\
\hline Endalamaw et al., 2018 [17] & Amhara & RFS & Children & 60 & 352 & 34 & 1294.7 & 2.63 & Good \\
\hline Beshir et al., 2019 [15] & Oromia & RFS & Children & 60 & 428 & 67 & 1109.6 & 6.04 & Good \\
\hline Alemu et al., 2016 [18] & Amhara & RFS & Children & 60 & 645 & 79 & 1854.0 & 4.26 & Good \\
\hline Jerene et al., 2017 [19] & AA\&SNNP & RFS & Adults & 84 & 660 & 64 & 2843.5 & 2.25 & Good \\
\hline Ahmed et al., 2017 & Afar & RFS & Adults & 84 & 451 & 119 & 1377.4 & 8.64 & Good \\
\hline Temesgen, 2017 & Amhara & RFS & Adults & 60 & 492 & 83 & 1285.5 & 6.46 & Good \\
\hline Dalbo and Tamiso, 2016 [20] & SNNP & RFS & Adults & 72 & 496 & 106 & 1977.6 & 5.36 & Good \\
\hline Assefa et al., 2014 [21] & Amhara & RFS & Adults & 42 & 400 & 136 & 1181.8 & 2.20 & Good \\
\hline Alene et al., 2013 [11] & Amhara & RFS & Adults & 60 & 470 & 26 & 1724.1 & 7.89 & Good \\
\hline Kassa et al., 2012 [22] & $\mathrm{AA}$ & RFS & Adults & 60 & 4210 & 270 & 8792.3 & 3.07 & Good \\
\hline
\end{tabular}

RFS retrospective follow-up study, $P M O$ person month observation, IR incidence rate 
tuberculosis with data from $\geq 10$ studies, we performed meta-regression analyses to calculate the hazard ratio (HR). Besides, we carried out a leave-one-out sensitivity analysis to evaluate the key studies that exert a major impact on between-study heterogeneity. The small study effect was assessed by a funnel plot and Egger's regression tests [24-26].

\section{Results}

\section{Search results}

The combined literature search strategy retrieved a total of 189 potential studies, of which 3 records were articles by manual search sources, 32 were screened for full-text review, and 11 studies were eligible to be included in the systematic and meta-analysis (Fig. 1).

\section{Description and risk bias assessment of the included studies}

Eleven articles that were published from 2010 to 2019 in different parts of Ethiopia from international peerreviewed and national journals included estimating incidence and predictors of tuberculosis among HIVinfected patients. A total sample size of 8875 participants was involved in the final analysis. Among these, 1036 were new tuberculosis cases from 2010 to 2019 published years. The sample size of included studies ranged from 271 [13] to 4210 [22] subjects. All of the reviewed studies were retrospective follow-up studies with a follow-up duration for assessing the outcome ranges from 42 to 84 months $[11-15,17-22]$.

Findings from a review of studies showed that the highest and lowest incidence rate of tuberculosis among HIV patients was in the Afar [12] and Amhara regions [21] which were 8.64 and 2.22 per 100 person-year observations respectively $[12,21]$ (Table 1 ). The majority of the studies reported that being ambulatory and/or bedridden, being anemic, being on WHO clinical staging III and IV, being males, having CD4 less than 200 cells/ $\mathrm{mm} 3$, having a history of tuberculosis, and being not on $\mathrm{CPT}$ and IPT were significant positive predictors for the incidence of tuberculosis among HIV-positive patients after initiation of ART.

\section{The pooled incidence of TB among HIV-infected patients on ART}

All eleven articles provided information on the incidence of tuberculosis among PLHIV in Ethiopia [11-15, 17-22]. Based on the random-effects method, pooled incidence rate of TB per 100-person-year observations among HIV-infected patients on ART was 4.8 (95\% CI 3.695.83) and heterogeneity was considerable $\left(I^{2}=94.1 \%\right.$, $Q=170, \mathrm{DF}=10$, variance $=2.97, z=8.7, p<0.0001)($ Fig. 2$)$.

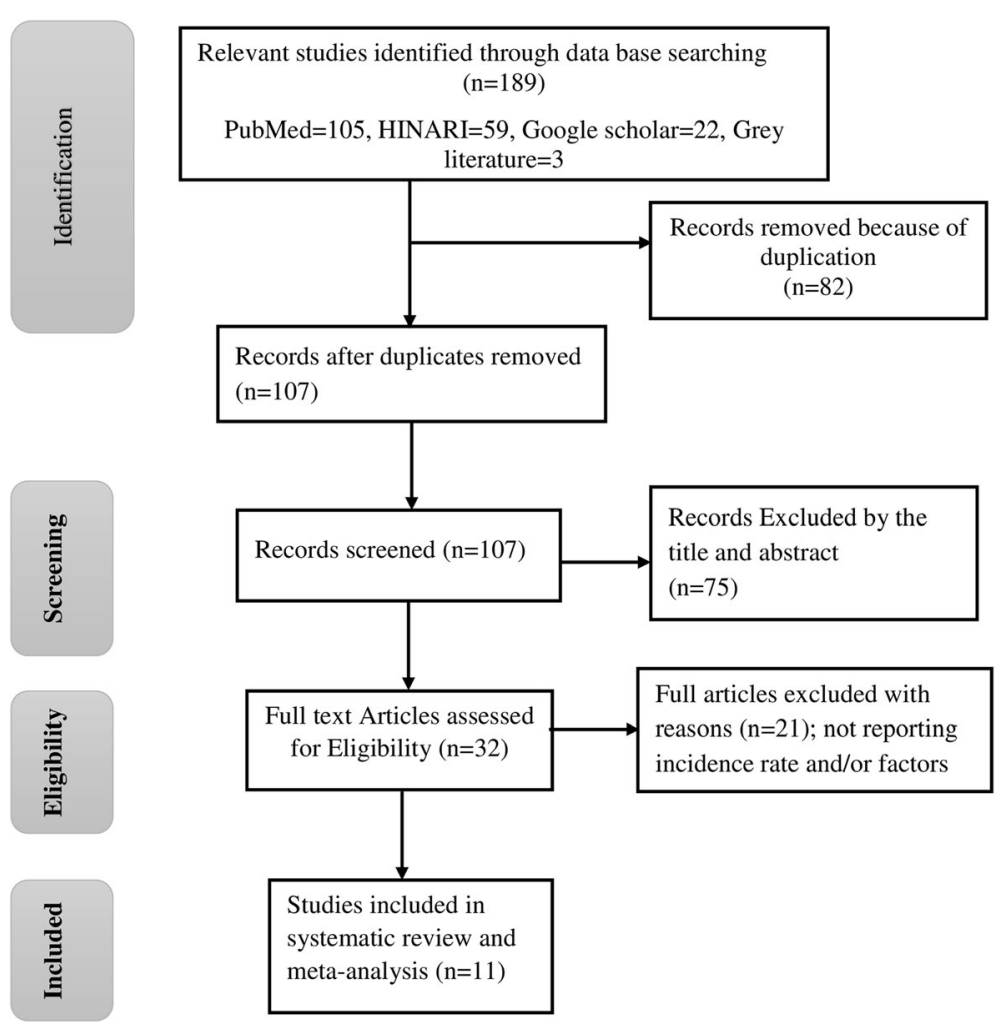

Fig. 1 PRISMA flow diagram for the studies screened, reviewed, and included in Ethiopia, 2020 


\section{Tuberculosis among HIV patients}

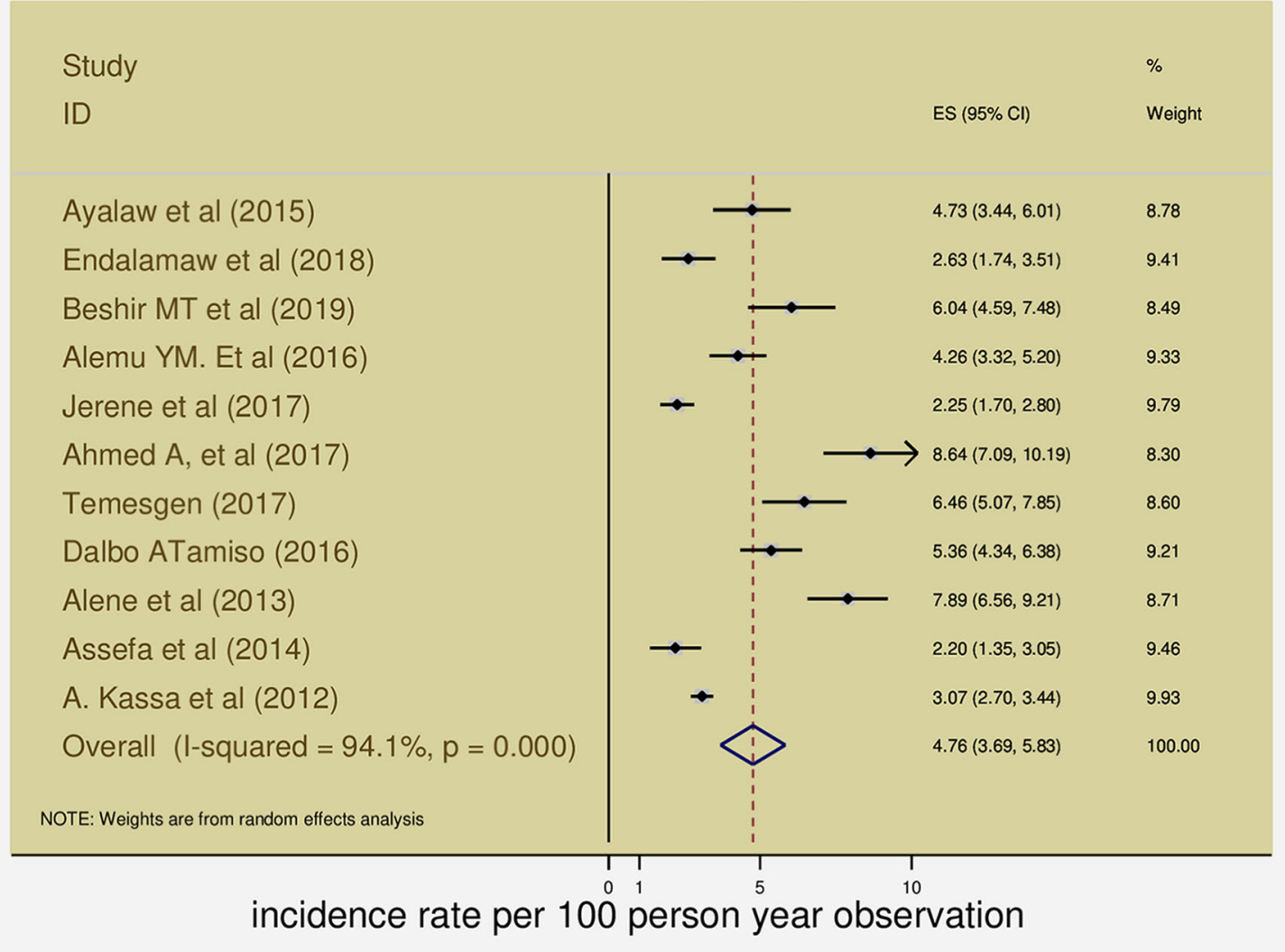

Fig. 2 The forest plots of the incidence rate of tuberculosis among HIV-infected patients in Ethiopia

Subgroup analyses of tuberculosis incidence among HIVinfected patients on ART

We conducted subgroup analysis based on the predefined category of study setting, study population, and length of follow-up time to determine the incidence of tuberculosis.

In our subgroup analysis, the incidence of tuberculosis among PLWHIV with studies in hospital-based was slightly lesser than facility-based studies $(4.7 ; 95 \% \mathrm{CI}$ 3.46, 5.97 vs 5.0 ; $95 \%$ CI 1.92, 8.01).

We also conducted a subgroup analysis based on the follow-up period for the sampled population. The pooled incidence of tuberculosis among HIV-infected patients after initiation of ART with 60 months or more followup period was significantly higher compared to less than 60-month follow-up period $(5.1 ; 95 \%$ CI 3.64, 6.46) compared to a longer period of follow-up time $(4.1 ; 95 \% \mathrm{CI}$ $1.87,6.27)$.
In the analyses stratifying summary estimates of TB incidence rates in the above categories, heterogeneity remained high for each stratum. This implied that these variables did not explain most of the heterogeneity observed in the $\mathrm{TB}$ incidence rate (Table 2).

We also performed a subgroup analysis based on the study population to determine the incidence rate of tuberculosis among HIV patients. Four studies were on children and the rest were about adult people. The pooled incidence rate tuberculosis in people living with HIV was 4.3 (95\% CI 2.96, 5.71) and 5.0 (95\% CI 3.51, 6.50) for the studies conducted on children and adults respectively (Fig. 3).

\section{Sensitivity analysis}

We performed a leave-one-out sensitivity analysis for the sake of further investigating potential sources of 
Table 2 Incidence of tuberculosis in people with HIV in Ethiopia: subgroup meta-analysis and heterogeneity analysis

\begin{tabular}{|c|c|c|c|c|c|c|c|c|}
\hline Subgroup types & Observation $(N)$ & IR per 100 PYO & $95 \% \mathrm{Cl}$ & $I^{2}(\%)$ & Q-statistic & $\mathrm{Tau}^{2}$ & Df & $P$ value \\
\hline \multicolumn{9}{|l|}{ Study setting } \\
\hline Hospital based & 8 & 4.7 & {$[3.46,5.97]$} & 93.3 & 104.9 & 2.95 & 7 & $P<0.0001$ \\
\hline Facility based & 3 & 5.0 & {$[1.92,8.01]$} & 96.8 & 63.4 & 6.95 & 2 & $P<0.0001$ \\
\hline \multicolumn{9}{|l|}{ Study population } \\
\hline Children & 4 & 4.3 & {$[2.96,5.71]$} & 83.7 & 18.5 & 1.61 & 3 & $P<0.0001$ \\
\hline Adults & 7 & 5.0 & {$[3.51,6.50]$} & 95.9 & 148.1 & 3.77 & 6 & $P<0.0001$ \\
\hline \multicolumn{9}{|l|}{ Follow-up period (months) } \\
\hline Less than or equal to 60 & 8 & 5.1 & {$[3.64,6.46]$} & 94.7 & 132.8 & 5.80 & 7 & $P<0.0001$ \\
\hline Greater than 60 & 3 & 4.1 & {$[1.87,6.27]$} & 94.1 & 34.0 & 3.53 & 2 & $P<0.0001$ \\
\hline
\end{tabular}

heterogeneity in the analysis of the incidence rate of tuberculosis in PLWHIV. Our sensitivity analysis showed that our findings were not influenced by a single study that all the point estimates of the leaveone-out are within the confidence interval of the combined estimate and it is stable. Our pooled estimated incidence varied between 4.4 (3.39-5.38) and
5.0 (3.85-6.23) after the deletion of a single study (see Table 3 and Fig. 4).

\section{Publication bias}

The funnel plot and Egger's regression tests showed that there is no evidence of substantial publication bias for

\section{Tuberculosis among HIV patients by study population}

Study

ID
ES $(95 \% \mathrm{Cl}) \quad$ Weight

children

Ayalaw et al (2015)

Endalamaw et al (2018)

Beshir MT et al (2019)

Alemu YM. Et al (2016)

Subtotal $($ I-squared $=83.7 \%, p=0.000)$

Adults

Jerene et al (2017)

Ahmed A, et al (2017)

Temesgen (2017)

Dalbo ATamiso (2016)

Alene et al (2013)

Assefa et al (2014)

A. Kassa et al (2012)

Subtotal (I-squared $=95.9 \%, p=0.000)$

Overall $($ I-squared $=94.1 \%, p=0.000)$

NOTE: Weights are from random effects analysis

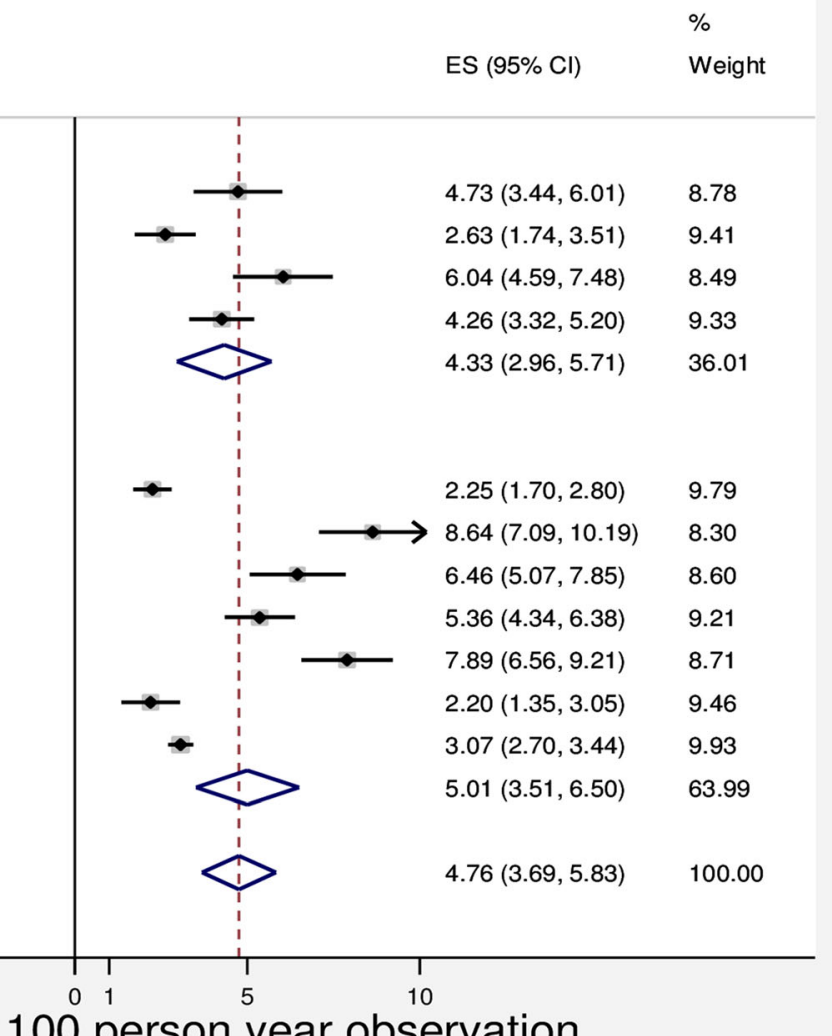

incidence rate per 100 person year observation

Fig. 3 Forest plot of subgroup analysis of the incidence of tuberculosis among HIV-infected patients by study population in Ethiopia 
Table 3 Sensitivity analysis for the incidence rate of tuberculosis among HIV-infected patients in Ethiopia

\begin{tabular}{ll}
\hline Study omitted & Estimate [95\% Cl] \\
\hline Ayalaw et al. (2015) [13] & $4.8(3.63,5.90)$ \\
Endalamaw et al. (2018) [17] & $5.0(3.82,6.16)$ \\
Beshir et al. (2019) [15] & $4.6(3.53,3.74)$ \\
Alemu et al. (2016) [18] & $4.8(3.65,5.99)$ \\
Jerene et al. (2017) [19] & $5.0(3.85,6.23)$ \\
Ahmed et al. (2017) & $4.4(3.39,5.38)$ \\
Temesgen et al. (2017) & $4.6(3.51,5.68)$ \\
Dalbo and Tamiso (2016) [20] & $4.7(3.57,5.82)$ \\
Assefa et al. (2014) [21] & $5.0(3.87,6.19)$ \\
Alene et al. (2013) [11] & $4.4(3.43,5.43)$ \\
Kassa et al. (2012) [22] & $5.0(3.63,6.32)$ \\
Combined & $4.8(3.69,5.83)$ \\
\hline
\end{tabular}

the incidence of tuberculosis among HIV infected patients in Ethiopia (see Additional files 1 and 2).

Pooled estimated effects of predictors on the incidence of tuberculosis

Meta-analysis was conducted to identify pooled estimates of predictors for the incidence of tuberculosis among HIV-infected individuals after the initiation of ART in Ethiopia. Among pooled estimates of predictors bedridden functional status, anemia status, WHO clinical staging, cotrimoxazole preventive therapy, isoniazid preventing therapy, CD4 cell count, and gender were found to be significant predictors for the incidence of tuberculosis whereas ambulatory functional status, previous history of tuberculosis, past opportunistic infections, and family size were not statistically significantly pooled predictor estimates for the incidence of tuberculosis among HIV-infected individuals in Ethiopia.

The risk of developing tuberculosis among HIVinfected anemic individuals for the pooled estimates of four observations was 2.3 times more likely as compared to those who had no anemia (HR 2.30; 95\%CI 1.75, 3.02; $I^{2}(p$ value $)=31.2 \%(0.18)$; publication bias: $\beta$ ( $p$ value $)$ $=0.82(0.60))$.

The risk of tuberculosis among HIV-infected individuals who are on WHO clinical stages III and IV was 2.26 times higher than those on WHO clinical stages I and II using meta-analysis of 10 studies (HR 2.26; 95\%CI 1.70, 3.02; $I^{2}$ (test) $=47.2 \%(p=0.048)$; publication bias: $\beta(p$ value $)=-0.13(0.90))$ (Table 4$)$.

The risk of developing tuberculosis among HIVinfected individuals for those not using CPT was 2.16 times more likely than CPT users using five articles (HR 2.16; 95\%CI 1.23, 3.72; $I^{2}$ (test) $=55.3 \%(p=0.062)$; publication bias: $\beta$ ( $p$ value $)=-1.37(0.54))$.

The risk of TB among male HIV-infected individuals was $37 \%$ higher compared to female patients using five articles (HR 1.37; 95\%CI 1.16, 1.63; $I^{2}$ (test) $=0(p=0.59)$; publication bias: $\beta(p$ value $)=-2.88$ (0.01)).

Since the heterogeneity of the variables not using IPT and CD4 count was high, further analysis by metaregression was required to manage it (Table 5).

\section{Meta-regression for high heterogeneity variables}

Isoniazid preventive therapy was a statistically significant predictor for the incidence of tuberculosis among HIV infected individuals for seven articles. The risk of developing tuberculosis among HIV-infected individuals for

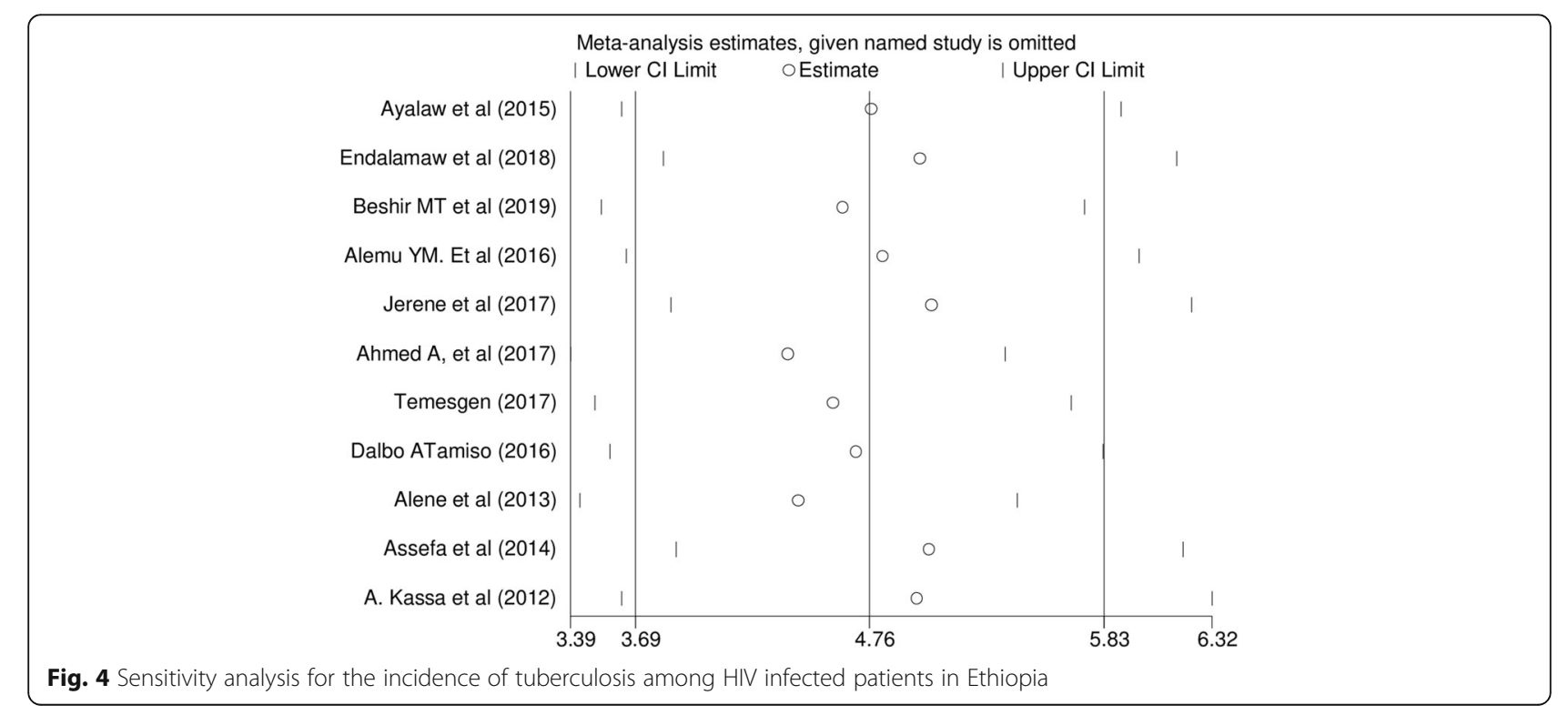


Table 4 A meta-analysis of predictors of incidence of tuberculosis among HIV-positive patients in Ethiopia (2010-2019)

\begin{tabular}{|c|c|c|c|c|c|c|c|c|}
\hline Variables & Observation & HR & $95 \% \mathrm{Cl}$ & $p$ value of $Q$ & $I^{2}(\%)$ & $\mathrm{Tau}^{2}$ & Q-statistic & $P$ value of estimate \\
\hline \multicolumn{9}{|l|}{ Functional status } \\
\hline Working (ref) & 4 & 1 & & & & & & \\
\hline Ambulatory & & 1.46 & {$[0.84,2.51]$} & $p=0.001$ & 78.8 & 0.29 & 18.83 & $p=0.18$ \\
\hline Bedridden & & 2.01 & {$[1.21,3.35]$} & $p=0.137$ & $42.7 \%$ & 0.13 & 6.98 & $p=0.007$ \\
\hline \multicolumn{9}{|l|}{ Anemia status } \\
\hline Not anemic (ref) & 8 & 1 & & & & & & $p<0.001$ \\
\hline Anemic & & 2.30 & {$[1.75,3.02]$} & $p=0.179$ & 31.2 & 0.05 & 10.17 & \\
\hline \multicolumn{9}{|l|}{ WHO clinical staging } \\
\hline Stage I/II (ref) & 10 & 1 & & & & & & $p<0.001$ \\
\hline Stage III/IV & & 2.26 & {$[1.70,3.02]$} & $p=0.048$ & 47.2 & 0.09 & 17.05 & \\
\hline \multicolumn{9}{|c|}{ Cotrimoxazole preventive therapy } \\
\hline Yes(ref) & 5 & 1 & & & & & & $p=0.007$ \\
\hline No & & 2.16 & {$[1.23,3.72]$} & $p=0.062$ & 55.3 & 0.20 & 8.95 & \\
\hline \multicolumn{9}{|l|}{ Isoniazid preventing therapy } \\
\hline Yes (ref) & 7 & 1 & & & & & & $p=0.001$ \\
\hline No & & 3.67 & {$[1.73,7.76]$} & $p<0.001$ & 79.1 & 0.74 & 28.7 & \\
\hline \multicolumn{9}{|l|}{ CD4 cell count } \\
\hline Greater than 200 & 6 & 1 & & & & & & $p=0.002$ \\
\hline Less than or equal to 200 & & 2.12 & {$[1.31,3.43]$} & $p<0.001$ & 90.8 & 0.32 & 54.38 & \\
\hline \multicolumn{9}{|l|}{ Previous history of tuberculosis } \\
\hline No & 3 & 1 & & & & & & \\
\hline Yes & & 1.49 & {$[0.77,2.89]$} & $p=0.004$ & 73.5 & 0.39 & 15.11 & $p=0.24$ \\
\hline \multicolumn{9}{|l|}{ Gender } \\
\hline Female & 5 & 1 & & & & & & \\
\hline Male & & 1.37 & {$[1.16,1.63]$} & $p=0.588$ & 0 & 0 & 2.82 & $p<0.001$ \\
\hline \multicolumn{9}{|l|}{ Family size } \\
\hline Less than five & & 1 & & & & & & \\
\hline Five or more & 3 & 1.18 & {$[0.89,1.56]$} & $p=0.29$ & 19.0 & 0.01 & 2.47 & $p=0.26$ \\
\hline
\end{tabular}

Table 5 Meta-regression of selected predictors to the incidence of tuberculosis among HIV-positive patients in Ethiopia (2010-2019)

\begin{tabular}{|c|c|c|c|c|c|c|c|c|}
\hline \multirow[t]{2}{*}{ Study level variables } & \multicolumn{4}{|l|}{ Low CD4 count } & \multicolumn{4}{|l|}{ Not using IPT } \\
\hline & HR with 95\% Cl & $I^{2}$ & $\mathrm{Tau}^{2}$ & $\operatorname{Adj.} R^{2}$ & HR with $95 \% \mathrm{Cl}$ & $I^{2}$ & $\mathrm{Tau}^{2}$ & Adj. $R^{2}$ \\
\hline \multicolumn{9}{|l|}{ Study population } \\
\hline Children & Ref. & & & & & & & \\
\hline Adults & $2.12[1.17,3.86]$ & $90.6 \%$ & 0.28 & 0 & $2.94[0.50,17.02]$ & $71.4 \%$ & 0.52 & $25.97 \%$ \\
\hline \multicolumn{9}{|l|}{ Study setting } \\
\hline Health facility-based & Ref. & & & & & & & \\
\hline Hospital based & $0.96[0.21,4.44]$ & $92.6 \%$ & 0.36 & $26.5 \%$ & $0.31[0.06,1.63]$ & $69.2 \%$ & 0.44 & $37.93 \%$ \\
\hline \multicolumn{9}{|l|}{ Follow-up time (years) } \\
\hline$\leq 5$ & Ref. & & & & & & & \\
\hline$>5$ & $2.18[0.73,6.50]$ & $78.4 \%$ & 0.15 & $46.05 \%$ & $0.53[0.06,5.08]$ & $68.4 \%$ & 0.68 & $3.61 \%$ \\
\hline
\end{tabular}


those not using IPT was 3.47 times more likely than IPT users (HR 3.67; 95\%CI 1.73,7.76; $I^{2}$ (test) $=79.1 \%(p<$ $0.001)$; publication bias: $\beta$ ( $p$ value $)=3.47(0.14))$. Metaregression revealed that not using IPT in the adults' study group was higher than children for the incidence of tuberculosis (HR 2.12; 95\% CI 1.17, 3.86).

CD4 count at baseline of ART initiation was a significant pooled factor for developing tuberculosis among six articles. The risk of tuberculosis incidence among HIV-infected individuals was 2.12 times more likely for those who had less than 200 cells $/ \mathrm{mm}^{3}$ at baseline than greater CD4 cell count $\left(\right.$ HR 2.12; 95\%CI 1.31, 3.43; $I^{2}$ (test) $=90.8 \%(p<0.001)$; publication bias: $\beta(p$ value $)=-3.16(0.57))$.

\section{Discussion}

Studies with tuberculosis incidence conducted among HIV patients in different regions of Ethiopia were included and carried out to determine the pooled incidence of tuberculosis among HIV-infected patients after ART initiation. Eleven studies that were published in scientific and reputable journals between 2010 and 2019 were included in this study.

Findings from a systematic review of included studies showed that the highest and lowest incidence rate of tuberculosis among HIV patients was observed in studies conducted in the Afar region and in the Amhara region which was 8.64 and 2.2 per 100 PYO respectively [12].

The current study revealed that the pooled TB incidence among HIV-infected patients after initiation of ART was 4.76 (95\% CI 3.69-5.83) per 100 PYO which was in line with the primary studies done in India in 2019 and Tanzania in 2015 which were 4.39 cases and 4.4 cases per $100 \mathrm{PYO}$, respectively [27, 28]. The current finding of pooled incidence was higher than studies conducted in higher-income countries in 2012, Asia in 2019, Brazil and Nigeria in 2017, and South Africa in 2005 which were $0.3,0.99,1.90,0.57$, and 2.44 per 100 person-years, respectively [29-33]. This difference might be because of the progressive development of latent to active TB disease due to the high incidence of HIV compared with higher-income countries [34] and this study also incorporated both children and adults. The other reason for the higher incidence might be a better casefinding strategy in Ethiopia. However, it was lower than the prospective community-based study done in South Africa in 2012 that was 7.4 per 100 PYO [5]. This difference might be all included primary studies in this paper which were retrospective cohort studies and health facility-based studies.

Subgroup analysis by study population of the current study showed that the pooled TB incidence among adults and children was slightly different which were 5.01 (95\% CI 3.51, 6.50) and 4.34 (95\% CI 2.96, 5.71) respectively. This finding was consistent with studies done in India in 2019 and Tanzania in 2015 which were 4.39 cases and 4.4 cases per 100 PYO, respectively [27, 28]. This might be the same socioeconomic status between these countries.

The current meta-analysis of the predictors showed that being anemic patients were a 2.30 higher risk for incidence of tuberculosis among HIV-infected individuals than non-anemic (HR 2.30, 95\% CI 1.75, 3.02). This might be due to the reason that anemia leads to the development of infections including tuberculosis by impairing the function of hemoglobin.

Our findings also showed that patients on advanced WHO clinical stages (III and IV) were 2.26 times greater risk of developing TB (HR 2.26, 95\% CI 1.70, 3.02). This was supported by several studies $[6,28,35]$. This is since being stages III and IV will have low CD4 cell count and ultimately be unable to defend against infections including tuberculosis.

This finding also revealed that patients with severe immunosuppression $\left(\mathrm{CD} 4 \%<200 \mathrm{cell} / \mathrm{mm}^{3}\right)$ were 2.12 times higher risk of developing $\mathrm{TB}$ than those with higher CD4 in adults. This was consistent with various studies $[28,29,32,35,36]$ in which severe immune suppression fastened the progression of latent TB to active disease [2]. This is because HIV kills TB's protective immune cells among HIV patients. A prospective cohort study done in South Africa showed that TB incidence was nearly 7 times higher risk observed with persontime at CD4 cell counts, 100 cells $/ \mathrm{mL}$ compared with person-time at CD4 cell counts 700 cells $/ \mathrm{mL}$ [5].

This meta-analysis study revealed that HIV patients without taking IPT were 3.67 times more at risk of developing new active TB than those taking IPT despite lifelong HAART (HR 3.67, 95\% CI 1.73, 7.76). Our study was consistent with the study done in Brazil in 2007 [30] which revealed that TB incidence with no IPT was higher. It was also supported by a meta-analysis study done in Ethiopia in which using IPT reduced TB incidence by $74 \%$ [37] and another study done in Ethiopia in 2014 [38]. Several studies also showed that TB incidence among those patients on IPT prophylaxis was reduced compared with none-IPT groups [39].

This study also showed that HIV patients without CPT were 2.16 times more hazards of developing TB than their counterparts [HR 2.2, 95\% CI 1.23, 3.72]. This was supported by a study done in Asia in 2019 which revealed CPT reduced TB incidence by $28 \%$ [31]. This may be since CPT protects at least five types of opportunistic disease among HIV patients that worsened immunosuppression and progression of the disease.

This study identified that previous TB treatment was not a significant predictor of TB incidence. This was in line with the cohort national study conducted in South Africa [33]. 
Generally, the current study was focused on the incidence of tuberculosis and its predictors among HIV patients after initiation of ART which is critical to improving the quality of life for HIV-infected patients. As a result, programmers and policymakers in the area of HIV shall take this finding to improve and strengthen the existing strategies especially focusing on HIV patients after ART initiation. Moreover, it shall be taken as a baseline to health workers and other stakeholders to made early screening and prevention of TB in PLHIV as $\mathrm{TB}$ can occur in any course of HIV treatment.

\section{Strengths and limitations of this study}

More than one reviewer was involved in this systematic review and meta-analysis, and we used a comprehensive searching strategy. Moreover, during this review, we had also strictly followed the PRISMA guideline. This systematic review and meta-analysis study of TB incidence among HIV infected after ART initiation was the first at national by combining both children and adults.

In this systematic review and meta-analysis, we encountered some limitations. For example, the number of studies that are included is limited, which might affect the pooled estimate of tuberculosis incidence and predictors among HIV-infected individuals in Ethiopia. The retrospective nature of the designs restricts the assessment of all possible predictors that affect the incidence of $\mathrm{TB}$.

\section{Conclusions}

The qualitative part of this review showed that TB incidence ranges from 2.2 to 8.64 per 100-person-year observation (PYO), after initiation of ART whereas the meta-analysis showed the pooled estimate of this TB incidence was higher than in several African and Asian countries. The pooled TB incidence among adults and children was 5.0 and 4.3 per 100 PYO respectively.

This meta-analysis indicated that anemia, WHO clinical staging of three and four, and low CD4 cell counts were of significant effects for the high incidence of $\mathrm{TB}$ among HIV-positive patients receiving ART. However, isoniazid preventive therapy helps in reducing the incidence of tuberculosis among HIV-infected patients. Besides, the incidence of tuberculosis has a significant difference between children and adults. Moreover, this study also identified the high incidence of active TB among HIV-infected patients at facility-based areas compared to Hospitals. Thus, the Ethiopian government should strengthen the WHO's three strategies to reduce the high TB incidence among HIV patients. Besides, clinicians should strengthen ART adherence.

\section{Supplementary Information}

The online version contains supplementary material available at https://doi. org/10.1186/s41182-021-00306-2.

Additional file 1. Egger test for publication bias for incidences of tuberculosis in Ethiopia.

Additional file 2. The funnel plot and Egger's regression tests.

\section{Abbreviations}

ART: Antiretroviral treatment; BCG: Bacillus Chalmette-Guerin;

CPT: Cotrimoxazole preventive therapy; DM: Diabetes mellitus; HIV: Human immunodeficiency virus; IPT: Isoniazid preventive therapy; Ol: Opportunistic infections; PLHIV: People living with human immune virus; PYO: Person-year observation; TB: Tuberculosis; WHO: World Health Organization

\section{Acknowledgements}

We would like to thank and express our deepest-rooted gratitude to the University of Gondar, Departments of Epidemiology and Biostatics, for initiating to do this systematic review and meta-analysis.

\section{Authors' contributions}

MM, NM, GS, and DA designed the study, reviewed the literature, were responsible for selecting the study and quality assessment, extracted and analyzed the data, interpreted the results, drafted the manuscript, and reviewed the manuscript for its scientific content. All authors have read and approved the manuscript.

\section{Funding}

No funding organizations

\section{Availability of data and materials}

Data will be available from the corresponding author upon request other than the included articles.

Ethics approval and consent to participate Not applicable.

Consent for publication Not applicable.

\section{Competing interests}

The authors declare no competing interests.

\section{Author details}

${ }^{1}$ Department of Social and Public Health, College of Medicine and Health Sciences, Debre Tabor University, Debre Tabor, Ethiopia. ${ }^{2}$ University of Gondar Comprehensive Specialized Hospital, Gondar, Ethiopia. ${ }^{3}$ Department of Epidemiology and Biostatistics, Institute of Public Health, College of Medicine and Health Science, University of Gondar, Gondar, Ethiopia.

Received: 22 July 2020 Accepted: 9 February 2021

Published online: 25 February 2021

\section{References}

1. World Health Organization. Global tuberculosis report 2018. World Health Organization. 2018. Licence: CC BY-NC-SA 3.0 IGO. https://apps.who.int/iris/ handle/10665/274453.

2. Winter JR, Adamu AL, Gupta RK, Stagg HR, Delpech V, Abubakar I. Tuberculosis infection and disease in people living with HIV in countries with low tuberculosis incidence. Int J Tuberc Lung Dis. 2018;22(7):713-22.

3. Organisation WH. WHO global tuberculosis report: Advocacy-Toolkit. 2019.

4. Bassett IV, Wang B, Chetty S, Giddy J, Losina E, Mazibuko M, et al. Intensive tuberculosis screening for HIV-infected patients starting antiretroviral therapy in Durban, South Africa. Clin Infect Dis. 2010;51(7):823-9.

5. Gupta A, Wood R, Kaplan R, Bekker L-G, Lawn SD. Tuberculosis incidence rates during 8 years of follow-up of an antiretroviral treatment cohort in South Africa: comparison with rates in the community. Plos one. 2012;7(3): e34156. 
6. Iliyasu Z, Babashani M. Prevalence and predictors of tuberculosis coinfection among HIV-seropositive patients attending the Aminu Kano Teaching Hospital, northern Nigeria. J Epidemiol. 2009;19(2):81-7.

7. Mama M, Manilal A, Tesfa H, Mohammed H, Erbo E. Prevalence of pulmonary tuberculosis and associated factors among HIV positive patients attending antiretroviral therapy clinic at Arba Minch General Hospital, Southern Ethiopia. Open Microbiol J. 2018;12:163-71.

8. Organisation WH. WHO GLOBAL TB REPORT 2019: Country Profiles 2019.

9. UNAIDS. Joint United Nations Programme on HIV/AIDS (UNAIDS) DATA 2017. Contract No.: UNAIDS/JC2910E. 2017.

10. Mitku AA, Dessie ZG, Muluneh EK, Workie DL. Prevalence and associated factors of TB/HIV co-infection among HIV Infected patients in Amhara region, Ethiopia. Afr Health Sci. 2016;16(2):588-95.

11. Addis Alene K, Nega A, Wasie TB. Incidence and predictors of tuberculosis among adult people living with human immunodeficiency virus at the University of Gondar Referral Hospital, Northwest Ethiopia. BMC Infect Dis. 2013;13:292.

12. Ahmed A, Mekonnen D, Shiferaw AM, Belayneh F, Yenit MK. Incidence and determinants of tuberculosis infection among adult patients with HIV attending HIV care in north-east Ethiopia: a retrospective cohort study. BMJ Open. 2018;8(2):e016961.

13. Ayalaw SG, Alene KA, Adane AA. Incidence and predictors of tuberculosis among HIV positive children at the University of Gondar Referral Hospital, Northwest Ethiopia: a retrospective follow-up study. Int Sch Res Notices. 2015;2015:307810.

14. Belisty Temesgen, Getiye Dejenu Kibret, Mekonnen N, Alamirew, and, Alebel A. Incidence and predictors of tuberculosis among HIV positive adults on antiretroviral therapy at Debre Markos Referral Hospital, Northwest Ethiopia: a retrospective record review. 2018 .

15. Beshir MT, Beyene AH, Tlaye KG, Demelew TM. Incidence and predictors of tuberculosis among HIV-positive children at Adama Referral Hospital and Medical College, Oromia, Ethiopia: a retrospective follow-up study. Epidemiol Health. 2019;41:e2019028.

16. LA Moher D, Tetzlaff J, Altman DG. Systematic reviews and Meta-analyses. Plos Med. 2009;6(6):e1000097.

17. Endalamaw A, Engeda EH, Tezera N. Incidence of tuberculosis in children on antiretroviral therapy: a retrospective cohort study. BMC Res Notes. 2018; 11(1):745-9

18. Alemu YM, Andargie G, Gebeye E. High incidence of tuberculosis in the absence of isoniazid and cotrimoxazole preventive therapy in children living with HIV in Northern Ethiopia: a retrospective follow-up study. Plos One. 2016;11(4):e0152941.

19. Jerene D, Abebe W, Taye K, Suarez PG, Feleke Y, Hallstrom I, et al. Tuberculosis along the continuum of HIV care in a cohort of adolescents living with HIV in Ethiopia. Int J Tuberc Lung Dis. 2017;21(1):32-7.

20. Dalbo M, Tamiso A. Incidence and predictors of tuberculosis among HIV/ AIDS infected patients: a five-year retrospective follow-up study. Adv Infect Dis. 2016;6(02):70.

21. Assefa A, Gelaw B, Getnet G, Yitayew G. The effect of incident tuberculosis on immunological response of HIV patients on highly active antiretroviral therapy at the University of Gondar hospital, northwest Ethiopia: a retrospective follow-up study. BMC Infect Dis. 2014;14:468.

22. Kassaa A, Tekab A, Shewaamarec A, Jerened D. Incidence of tuberculosis and early mortality in a large cohort of HIV-infected patients receiving antiretroviral therapy in a tertiary hospital in Addis Ababa, Ethiopia. Transact R Soc Trop Med Hyg. 2012;106:363-70.

23. JBI_Critical_Appraisal-Checklist_for_Cohort_Studies. 2017.

24. Julian P T Higgins, Simon G Thompson, Deeks JJ, and, Altman DG. Measuring inconsistency in meta-analyses. BMJ. 2009;327:557-60.

25. AL. MBE. A basic introduction to fixed-effect and random-effects models for meta-analysis. Res Syn Meth. 2010(1):97--111.

26. Bradburn MJ, Deeks JJ, Altman DG. Meta-analysis in Stata. In: Sterne J, editor. metan, metacum, and metap; 1999

27. Gupte AN, Kadam D, Sangle S, Rewari BB, Salvi S, Chavan A, et al. Incidence of tuberculosis in HIV-infected adults on first- and second-line antiretroviral therapy in India. BMC Infect Dis. 2019;19(1):914.

28. Liu E, Makubi A, Drain P, Spiegelman D, Sando D, Li N, et al. Tuberculosis incidence rate and risk factors among HIV-infected adults with access to antiretroviral therapy. AIDS. 2015;29(11):1391-9.

29. Pathmanathan I, Dokubo EK, Shiraishi RW, Agolory SG, Auld AF, Onotu D, et al. Incidence and predictors of tuberculosis among HIV-infected adults after initiation of antiretroviral therapy in Nigeria, 2004-2012. Plos one. 2017; 12(3):e0173309.

30. Golub JE, Saraceni V, Cavalcante SC, Pacheco AG, Moulton LH, King BS, et al. The impact of antiretroviral therapy and isoniazid preventive therapy on tuberculosis incidence in HIV-infected patients in Rio de Janeiro, Brazil. AIDS. 2007;21(11):1441-8.

31. Ku SW, Jiamsakul A, Joshi K, Pasayan MKU, Widhani A, Chaiwarith R, et al. Cotrimoxazole prophylaxis decreases tuberculosis risk among Asian patients with HIV. Int AIDS Soc. 2019;22(3):e25264.

32. Collaboration TH-C. Impact of antiretroviral therapy on tuberculosis incidence among HIV-positive patients in high-income countries. Clin Infect Dis. 2012;54(9):1364-72.

33. Lawn SD, Badri M, Wood R. Tuberculosis among HIV-infected patients receiving HAART: long-term incidence and risk factors in a South African cohort. AIDS. 2005;19(18):2109-16.

34. Williams BG, Granich R, De Cock KM, Glaziou P, Sharma A, Dye C. Antiretroviral therapy for tuberculosis control in nine African countries. Proc National Acad Sci. 2010;107(45):19485-9.

35. Auld AF, Mbofana F, Shiraishi RW, Alfredo C, Sanchez M, Ellerbrock TV, et al. Incidence and determinants of tuberculosis among adults initiating antiretroviral therapy-Mozambique, 2004-2008. Plos one. 2013:8(1):e54665.

36. Suthar AB, Lawn SD, del Amo J, Getahun H, Dye C, Sculier D, et al. Antiretroviral therapy for prevention of tuberculosis in adults with HIV: a systematic review and meta-analysis. Plos Med. 2012;9(7):e1001270.

37. Geremew D, Endalamaw A, Negash M, Eshetie S, Tessema B. The protective effect of isoniazid preventive therapy on tuberculosis incidence among HIV positive patients receiving ART in Ethiopian settings: a meta-analysis. BMC Infect Dis. 2019;19(1):405.

38. Yirdaw KD, Jerene D, Gashu Z, Edginton ME, Kumar AM, Letamo Y, et al. Beneficial effect of isoniazid preventive therapy and antiretroviral therapy on the incidence of tuberculosis in people living with HIV in Ethiopia. Plos One. 2014;9(8):e104557.

39. Umeokonkwo CD, Segun B, Nguku P, Shakir M, Balogun PN, Bulage L, et al. Effectiveness of isoniazid preventive treatment among patients on antiretroviral treatment in Southeast Nigeria: A retrospective cohort study. J Interv Epidemiol Public Health. 2018;1:9.

\section{Publisher's Note}

Springer Nature remains neutral with regard to jurisdictional claims in published maps and institutional affiliations.
Ready to submit your research? Choose BMC and benefit from:

- fast, convenient online submission

- thorough peer review by experienced researchers in your field

- rapid publication on acceptance

- support for research data, including large and complex data types

- gold Open Access which fosters wider collaboration and increased citations

- maximum visibility for your research: over $100 \mathrm{M}$ website views per year

At BMC, research is always in progress.

Learn more biomedcentral.com/submissions 